
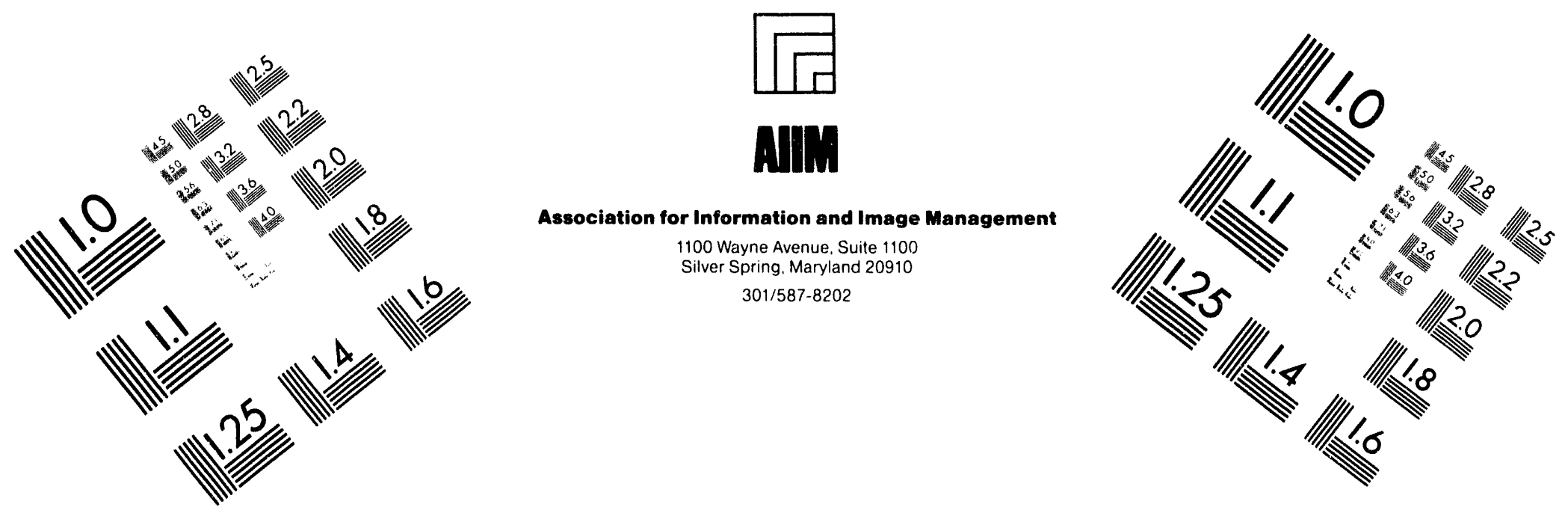

\title{
Centimeter
}

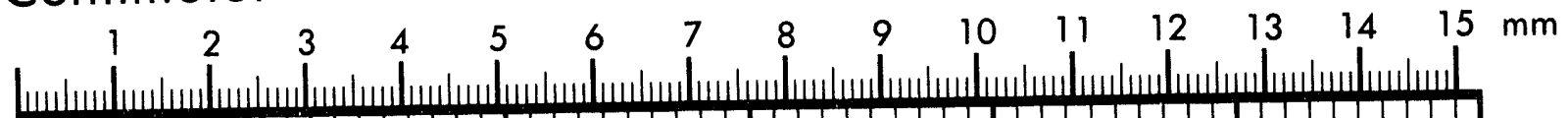

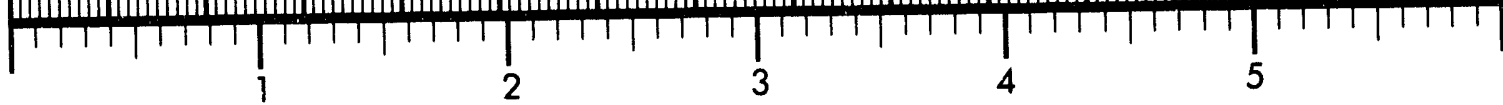
Inches
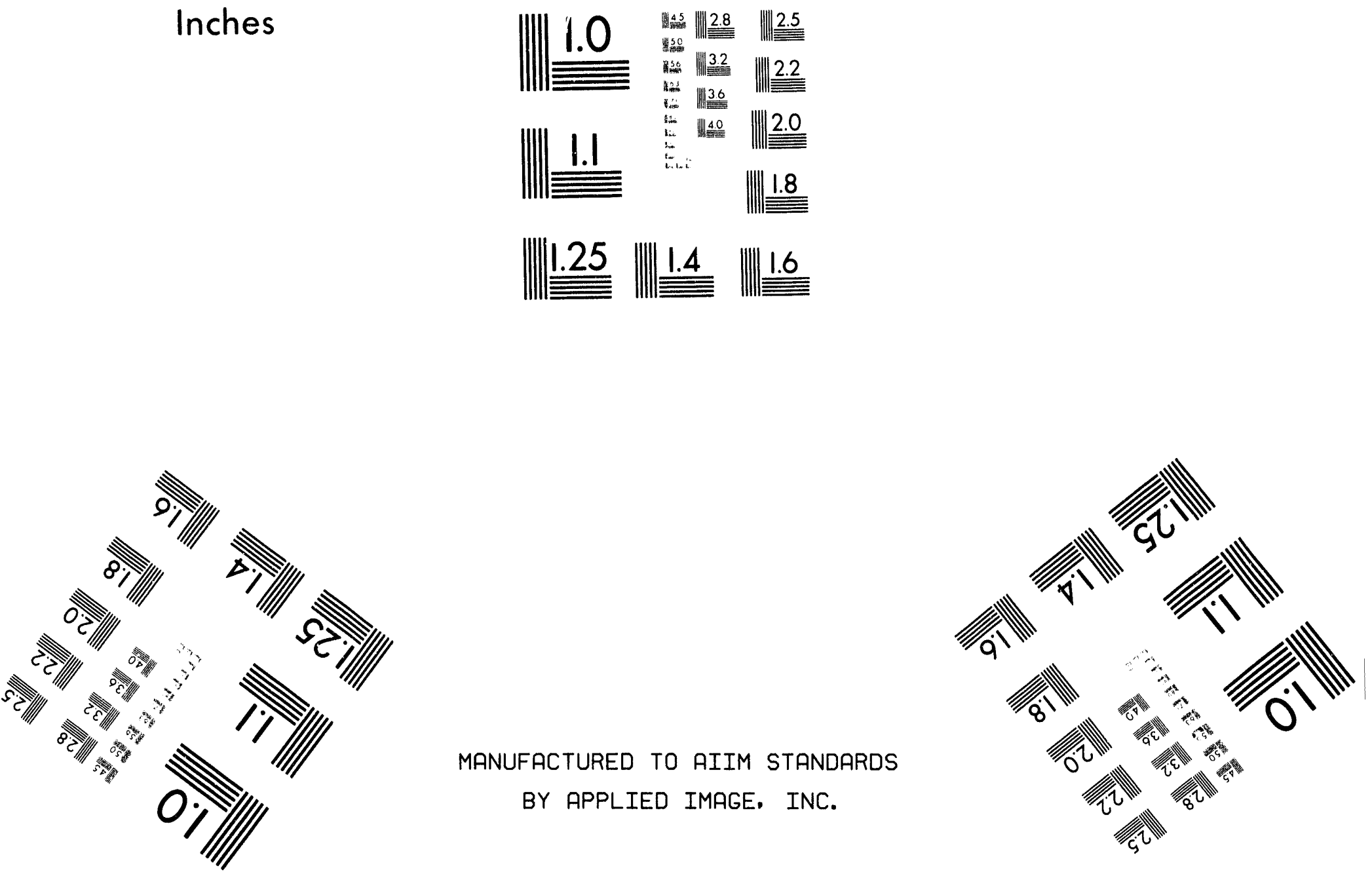

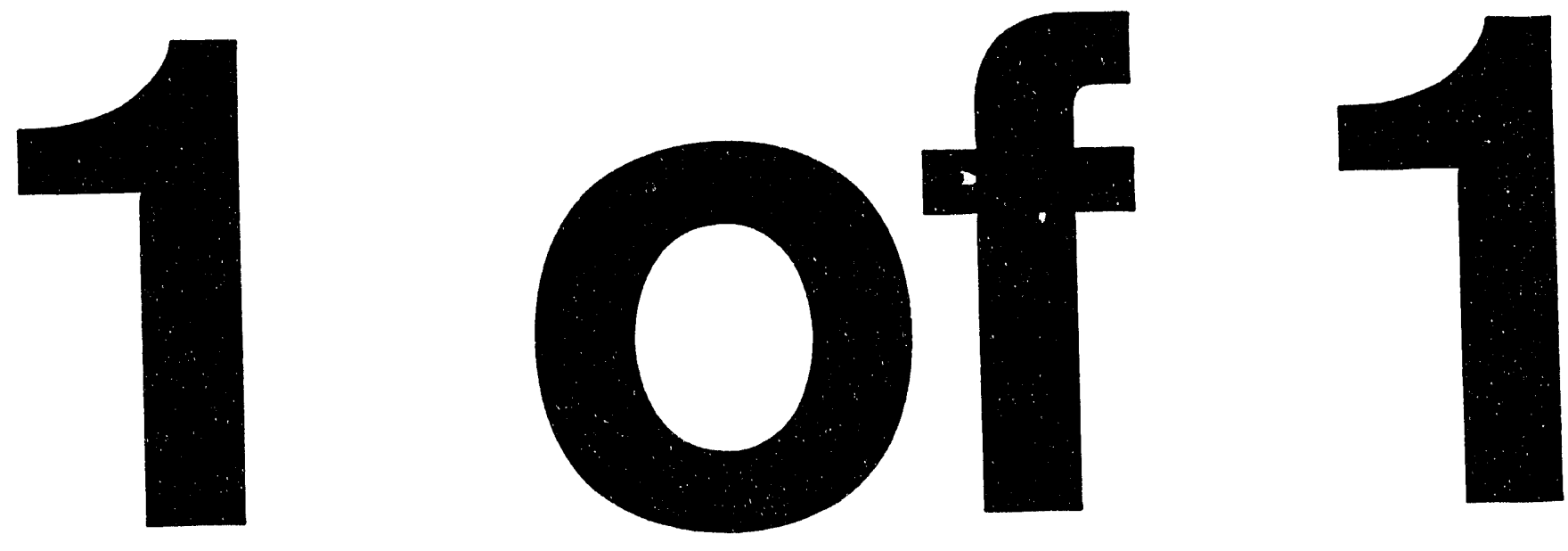


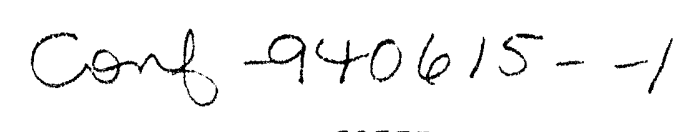

BNL-60555

Presented at 15th International Cryogenic Engineering Conference, Genova, Italy, June 7-10.1994

\section{DESIG. PARAMETERS FOR GAS-COOLED ELECTRICAL LEADS OF THE g-2 MAGNETS}

L. X. Jia. L. J. Addessi, J. R. Cullen Jr.. A. J. Esper, R. E. Meier, C. Pai, L. P. Snydstrup

Brookhaven National Laboratory, Upton, NY 11973, U.S.A.

M. A. Green

Lawrence Berkeley Laboratory, Berkeley, CA 94720, U.S.A.

This report presents the design parameters for a pair of $5300 \mathrm{~A}$ gas-cooled electrical leads for the g-2 solenoids and a pair of $2850 \mathrm{~A}$ leads for the inflector magnet. The lead design parameters are derived from a scale analysis of two onedimensional, thermo-fluid-electro-quasi-coupled, and non-linear differential equations. The analysis may apply to general gas-cooled electrical lead design. As an illustration, these design parameters are applied to multi-tube gas-cooled leads that are proposed for the g-2 solenoid magnet system. Multiple electrical current carrying tubes and multiple gas flow cooling channels will increase the lead current capacity and lead efficiency for enhanced heat transfer and low flow pressure drop.

\section{INTRODUCTION}

The g-2 storage ring magnet system consists of four large superconducting solenoids that are up to 15.1 $\mathrm{m}$ in diameter [1]. The four solenoids will be hooked in series and they will be powered through at single pair of $5300 \mathrm{~A}$ gas-cooled electrical leads. In addition there is an inflector magnet that is separately powered through a pair of $2850 \mathrm{~A}$ gas-cooled leads. Both sets of leads will be cooled using cold helium drawn directly from the forced two-phase helium cooling system used to cool the four solenoids and the inflector.

Tubular gas-cooled electrical leads have been used at various laboratories since the mid 1960's to power superconducting magnets. An insert was used to improve the heat transfer in tube leads in the late 1960's to increase the lead current by a factor of as much as three. The use of annular flow leads was described in the literature by Smits et al. in 1981 [2]. The concept of bundling tube leads to increase their current was applied to curved gas-cooled leads for the PEP-4 solenoid [2].

Gas-cooled electrical leads of many different kinds for superconducting magnets have been studied for over 25 years. M. N. Wilson's book [3] is an excellent source of information concerning the design of boil-off-gas-cooled electrical leads. Some lead design parameters for the "ideal gas-cooled leads" (i.e. the heat transfer coefficient is infinite) was given in the book. D. P. Sekulic et al. discussed the optimal thermal design of the "non-ideal gas-cooled leads" (i.e. the heat transfer coefficient is finite) using the entropy analysis [4].

This report presents some design parameters for non-ideal gas-cooled leads derived from a scale analysis on the energy balance, which may be applied to the general gas-cooled electrical lead design and allow one to get some design parameters in fair accuracy even before doing any detailed numerical computations. This analysis is based on the following assumptions: 1) Overall electrical heat generation in the lead is approximately equal to the overall convective heat flux from the lead to the cooling gas; 2) Overall convective heat flux of the lead is approximately equal to the overall enthalpy

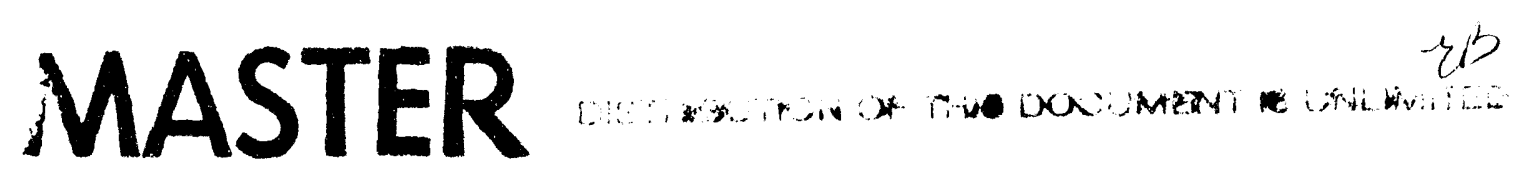


increase of the cooling gas; 3) Overall electrical heat generation of the lead is approximately twice as much as the overall conductive heat dissipation through the lead between the high and low temperature levels.

\section{GAS-COOLED LEAD MODEL}

The mathematical model in non-dimensional variables for gas-cooled electrical lead may be described by a set of two thermo-fluid-electro-quasi-coupled, non-linear. one-dimensional differential equations that are derived from an energy balance applied to a differential element of the electrical lead and the cooling gas flow. It takes the following form:

$$
\begin{aligned}
& \frac{d}{d \xi}\left[a(\theta) \frac{d \boldsymbol{\theta}}{d \xi}\right]+b(\boldsymbol{\theta}) \Gamma^{*}=B i^{*}(\boldsymbol{\theta}-\theta) \\
& \frac{d \boldsymbol{\theta}}{d \xi}=S t^{*}(\boldsymbol{\theta}-\boldsymbol{\theta})
\end{aligned}
$$

where $\Theta$ is the non-dimensional lead temperature, $\Theta=\left(T_{S}-T_{C}\right) /\left(T_{H}-T_{C}\right)$. $T_{H}$ and $T_{C}$ are the temperatures of lead at top and bottom, respectively. $T_{S}$ is the variable temperature of metal lead. $\theta$ is the nondimensional cooling gas temperature, $\theta=\left(T_{g}-T_{C}\right) /\left(T_{H}-T_{C}\right)$. $T_{g}$ is the variable temperature of gas flow. $\xi$ is the non-dimensional axial coordinate, $\xi=\mathrm{x} / \mathrm{L}$. a $(\Theta)$ is the non-dimensional thermal conductivity of the lead, $a(\Theta)=k(\Theta) / k_{\text {ref. }} b(\Theta)$ is the non-dimensional electrical resistivity of lead, $b(\Theta)=\rho(\Theta) / \rho_{\text {ref }} . k(\Theta)$ and $\rho(\Theta)$ are variable values for lead metal thermal conductivity and electrical resistivity, respectively. $\mathrm{k}_{\text {ref }}$ and $\rho_{\text {ref }}$ are their reference values taken at the same reference temperature $\mathrm{T}_{\text {ref. }} \Gamma^{*}, \mathrm{Bi}^{*}$ and $S t^{*}$ are non-dimensional functions which are given in the next few paragraphs.

\section{LEAD DESIGN PARAMETERS}

Electrical Heat Dissipation Parameter $=\underline{\mathrm{IL} / \mathrm{A}_{S}}$

The first non-dimensional function $\Gamma^{\circ}$ defined by Eq. (1) and known as the electrical power dissipation function relates the Joule heating to heat conducted down the lead. $\Gamma^{*}$ takes the following form:

$$
\Gamma^{*}=\frac{\left(I L / A_{B}\right)^{2} \rho_{\text {ref }}}{k_{\text {ref }}\left(T_{H}-T_{C}\right)}=\frac{\left(L / A_{s}\right) I^{2} \rho_{\text {ref }}}{A_{g} k_{\text {rof }}\left(T_{H}-T_{C}\right) / L}=\frac{\text { Electrical heat generation }}{\text { Conductive heat dissipation }}=S_{2}
$$

where $I$ is the electrical current. $L$ is the length of the lead. $A_{S}$ is the lead cross-section area. The IL/A $A_{S}$ term appeared in the function is found extensively in the gas-cooled lead literature. As pointed out earlier the electrical heat generation is approximately twice as much as the conductive heat dissipation, i.e. $S_{2}=2$ and thus $\Gamma^{*}=2$, approximately. IL/A thus takes the following form:

$$
I L / A_{s}=\left[S_{2} k_{x \theta f}\left(T_{H}-T_{C}\right) / \rho_{x \theta f}\right]^{0.5}=k_{r e f}\left\{S_{2}\left(T_{H}-T_{C}\right) / L O T_{r \theta t}\right]^{0.5}=\left[S_{2} L O T_{x \theta f}\left(T_{H}-T_{C}\right)\right]^{0.5} / \rho_{\text {ref }}
$$

The Wiedemann-Franz law, $\mathrm{k} \rho=\mathrm{LoT}\left(\mathrm{Lo}=2.45 \times 10^{-8} \mathrm{~W} \Omega \mathrm{K}^{-2}\right.$ ), has been applied to the last two terms of Eq. (4). The parameter IL/A for a lead can vary depending on the metal in the leads. The point is that for a given electrical current, there is a given value for $L / A_{S}$. The value for $I L / A_{S}$ for phosphorous deoxidized copper given in Wilson's book is $3.5 \times 10^{6} \mathrm{~A} \mathrm{~m}^{-1}$.

Heat Exchange Parameter $-\mathrm{PL}^{2} / \mathrm{A}_{S}$ 
The second non-dimensional function is the modified $\mathrm{Biot}$ number $\mathrm{Bi}^{*}$ or heat exchange function which is defined in Eq. 1 as follows:

$$
B i^{\circ}=\frac{h P L^{2}}{k_{\text {ref }} A_{s}}=\frac{h P L\left(T_{s}-T_{g}\right)\left[\left(T_{H}-T_{C}\right) /\left(T_{s}-T_{g}\right)\right]}{A_{g} k_{r o f}\left(T_{H}-T_{C}\right) / L}=\frac{\text { Convective heat flux }}{\text { Conduct ive heat dissipation }} \cdot R_{T}=S_{2} \cdot R_{T}
$$

where $h$ is the heat transfer coefficient. $P$ is the wetted perimeter. $R_{T}$ is the temperature ratio which is defined as $R_{T}=\left(T_{H}-T_{C}\right) /\left(T_{S}-T_{g}\right)$. For a typical gas cooled lead $T_{H}-T_{C}=300 \mathrm{~K}$ and $T_{S}-T_{g}=3$ to $6 \mathrm{~K}$ for a well designed lead. A reasonable design value for $R_{T}$ is about 100 . If one lets $S_{2}=2$ and $B i^{\circ}=$ 200 , approximately, the following relationship holds: $\mathrm{PL}^{2} / \mathrm{A}_{\mathrm{S}}=200 \mathrm{k}_{\mathrm{ref}} / \mathrm{h}$.

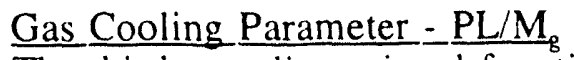

The third non-dimensional function is the modified Stanton number St or gas cooling function which is defined in Eq. (2) as following:

$$
S t^{*}=\frac{h P L}{M_{g} C_{p}}=\frac{h P L\left(T_{B}-T_{g}\right)\left[\left(T_{H}-T_{C}\right) /\left(T_{g}-T_{g}\right)\right]}{M_{g} C_{D}\left(T_{H}-T_{C}\right)}=\frac{\text { Corvective heat } f 1 u x}{\text { Gas enthalpy increase }} \cdot R_{T}=S_{1} \cdot R_{\text {: }}
$$

where $M_{g}$ is the gas mass flow rate. $C_{p}$ is the specific heat of cooling gas. Since $R_{T}$ has value of about 100 , if one lets $S_{1}=1$, the modified Stanton number $S t^{*}$ has a value of about 100 . Thus, the following relationship holds: $\mathrm{PL} / \mathrm{M}_{\mathrm{g}}=100 \mathrm{C}_{\mathrm{p}} / \mathrm{h}$.

\section{Mass Flow Rate Parameter $=\mathrm{M}_{\mathrm{g}} / \mathrm{I}$}

The mass flow rate parameter is defined by the ratio of the modified $\mathrm{Biot}$ number, $\mathrm{Bi}^{*}$, and the modified Stanton number, $\mathrm{St}^{*}$ :

$$
\frac{B i}{S t^{*}}=\frac{M_{g} C_{p} L}{A_{g} k_{\text {rof }}}=\frac{M_{g} C_{p}\left(T_{H}-T_{C}\right)}{A_{g} k_{\text {rof }}\left(T_{H}-T_{C}\right) / L}=\frac{\text { Gas enthalpy increase }}{\text { Conductive heat dissipation }}=S_{2}=\frac{I L}{A_{s}} \frac{M_{g}}{I} \frac{C_{p}}{k_{\text {rot }}}
$$

If one lets $\mathrm{S}_{2}=2$, and $\mathrm{Bi}^{*} / \mathrm{St}^{*}=2$, the following expression can be derived: $\mathrm{M}_{\mathrm{g}} / \mathrm{I}=2\left(\mathrm{k}_{\mathrm{ref}} / \mathrm{C}_{\mathrm{p}}\right)$ i (IL $\left.A_{\xi}\right)$ $=\left(\mathrm{S}_{2} \mathrm{LoT}_{\mathrm{ref}} / \Delta \mathrm{T}\right)^{0.5} / \mathrm{Cp}$. The mass flow rate per unit current can be estimated by using Eq. (7).

\section{Lead Efficiency Parameter - (IL/A 2 (L/M $)$}

The ratio of the electrical heat generation parameter and the mass flow rate parameter takes following form:

$$
\Gamma^{*} \frac{S t^{*}}{B i^{*}}=\frac{\left(L / A_{g}\right) I^{2} \rho_{\text {ror }}}{M_{g} C_{p}\left(T_{H}-T_{C}\right)}=\frac{\text { Electrical heat generation }}{\text { Gas enthalpy increase }}=S_{1}
$$

If one lets $S_{1}=1$, and $\Gamma^{*} \mathrm{St}^{*} / \mathrm{Bi}^{*}=1$, the following expression can be derived: $\left(\mathrm{IL} / \mathrm{A}_{\mathrm{S}}\right)\left(\mathrm{L} M \mathrm{M}_{\tilde{\xi}}\right)=$ $\mathrm{C}_{\mathrm{P}}\left(\mathrm{T}_{\mathrm{H}}-\mathrm{T}_{\mathrm{C}}\right) / \rho_{\text {ref }}=\mathrm{C}_{\mathrm{P}}\left(\mathrm{T}_{\mathrm{H}}-\mathrm{T}_{\mathrm{C}}\right) \mathrm{k}_{\text {ref }} f\left(\right.$ Lo $\left.\mathrm{T}_{\text {ref }}\right)$.

\section{MULTI-TUBE GAS-COOLED LEADS}

As an illustration, these design parameters are applied to the multi-tube gas-cooled leads that are proposed for the g-2 solenoid magnet system. A combination of three tubes with an insert tube which does not carry the electrical current has been chosen. Table 1 compares the performance of the gascooled leads in different combinations which may be used for the selection of multi-tube forms. Table 2 gives the geometries of a three-tube lead using standard Type $M$ copper tube (RRR = 6.365). The 
number of tube bundles was set at five for each $5300 \mathrm{~A} \mathrm{~g}-2$ solenoid gas cooled lead. A design current of $1060 \mathrm{~A}$ per tube in the bundle was used to determine the design of the nested tube set. For each 2850 A g-2 inflector lead, the number of tube bundles can be set at three. Table 3 gives the physical parameters of the g-2 leads [5]. Table 4 shows the numerical values of the modified heat transfer functions of the g-2 lead. Table 5 shows the numerical values of the design parameters of the g- 2 leads using Eqs. (3) to (8).

Table 1 Comparison of the performance of the gas-cooled leads in different combinations

\begin{tabular}{lll}
\hline Tube Form & $\mathrm{P}_{\mathrm{A}}$ & $\mathrm{A}_{\mathrm{S}} / \mathrm{I}$ \\
\hline One annular gas flow channel/one electrical current flow tube & 1 & 1 \\
Two annular gas flow channels/two electrical current flow tubes & $3 / 2$ & 2 \\
Two annular gas flow channels/three electrical current flow tube, & $4 / 3$ & 3 \\
Three annular gas flow channels/three electrical current flow tubes & $5 / 3$ & 3 \\
\hline
\end{tabular}

Table 2 Geometries of standard Type $M$ copper tubes used for the g-2 gas-cooled electrical leads

\begin{tabular}{lllll}
\hline & Outer Tube & Mid Tube & Inner Tube & Insert \\
\hline Tube O.D. $(\mathrm{mm})$ & 22.225 & 19.050 & 15.875 & 12.700 \\
Tube I.D. $(\mathrm{mm})$ & 20.599 & 17.526 & 14.453 & 10.210 \\
\hline
\end{tabular}

Table 3 Physical parameters of the g-2 gas-cooled electrical leads

\begin{tabular}{llllllllll}
\hline $\begin{array}{l}\mathrm{L} \\
(\mathrm{m})\end{array}$ & $\begin{array}{l}\mathrm{P} \\
(\mathrm{m})\end{array}$ & $\begin{array}{l}\mathrm{A}_{\mathrm{s}} \\
\left(\mathrm{m}^{2}\right)\end{array}$ & $\begin{array}{l}\mathrm{A}_{\mathrm{g}} \\
\left(\mathrm{m}^{2}\right)\end{array}$ & $\begin{array}{l}\mathrm{M}_{\mathrm{g}} \\
(\mathrm{g} / \mathrm{s})\end{array}$ & $\begin{array}{l}\mathrm{h} \\
\left(\mathrm{W} / \mathrm{m}^{2}-\mathrm{K}\right)\end{array}$ & $\begin{array}{l}\mathrm{I} \\
(\mathrm{A})\end{array}$ & $\begin{array}{l}\mathrm{T}_{\text {ref }} \\
(\mathrm{K})\end{array}$ & $\begin{array}{l}\rho_{\text {ref }} \\
(\Omega \mathrm{m})\end{array}$ & $\begin{array}{l}\mathrm{k}_{\text {ref }} \\
(\mathrm{W} / \mathrm{m}-\mathrm{K})\end{array}$ \\
\hline 0.437 & 0.275 & $1.32 \times 10^{-4}$ & $1.29 \times 10^{-4}$ & 0.050 & 198 & 1060 & 273 & $1.81 \times 10^{-8}$ & 369.8 \\
\hline
\end{tabular}

Table 4 Numerical values of the modified heat transfer functions of the g-2 gas-cooled electrical leads

\begin{tabular}{lllll}
\hline$\Gamma^{*}$ & $\mathrm{Bi}^{*}$ & $\mathrm{St}^{*}$ & $\mathrm{Bi}^{*} / \mathrm{St}^{*}$ & $\Gamma^{*} \mathrm{St}^{*} / \mathrm{Bi}^{*}$ \\
\hline 2.03 & 212 & 92 & 2.3 & 0.88 \\
\hline
\end{tabular}

Table 5 Numerical values of the design parameters of the g-2 gas-cooled electrical leads

\begin{tabular}{l|l|l|l|l}
\hline $\mathrm{IL} / \mathrm{A}_{\mathrm{S}}(\mathrm{A} / \mathrm{m})$ & $\mathrm{PL}^{2} / \mathrm{A}_{\mathrm{S}}(\mathrm{m})$ & $\mathrm{PL} / \mathrm{M}_{\mathrm{g}}\left(\mathrm{m}^{2}-\mathrm{sec} / \mathrm{kg}\right)$ & $\mathrm{M}_{\mathrm{g}} / \mathrm{I}(\mathrm{kg} / \mathrm{sec}-\mathrm{A})$ & $\left(\mathrm{IL} / \mathrm{A}_{\mathrm{S}}\right) /\left(\mathrm{L} / \mathrm{M}_{\mathrm{g}}\right)$ \\
\hline $3.5 \times 10^{6}$ & 396 & 2403 & $4.72 \times 10^{-8}$ & $7.42 \times 10^{13}$ \\
\hline$\left(\mathrm{S}_{2} \mathrm{k}_{\mathrm{ref}} \Delta \mathrm{T} / \rho_{\mathrm{ref}}\right)^{-0.5}$ & $\left(\mathrm{~S}_{2} \mathrm{k}_{\mathrm{ref}} / \mathrm{h}\right) \times 100$ & $(\mathrm{Cp} / \mathrm{h}) \times 100$ & $\left(\mathrm{~S}_{2} \mathrm{LoT}_{\mathrm{ref}} / \Delta \mathrm{T}\right)^{0.5} / \mathrm{Cp}$ & $\mathrm{Cp} \Delta \mathrm{T} / \rho_{\mathrm{ref}}$ \\
\hline $3.48 \times 10^{6}$ & 374 & 2626 & $4.09 \times 10^{-8}$ & $8.49 \times 10^{13}$ \\
\hline
\end{tabular}


Gas-cooled electrical leads for the g-2 solenoids and the inflector can be built using bundled tube leads where each of the tubes in the bundle consists of nested standard Type $M$ copper tubes. Both of the 5300 A solenoid leads will fit in a cylinder that is $120 \mathrm{~mm}$ in diameter by $750 \mathrm{~mm}$ long. Both the 2850 A inflector leads will fit within a cylinder that is $100 \mathrm{~mm}$ in diameter by $650 \mathrm{~mm}$ long. Superconductor will be attached to the tubes in order to reduce the heat leak into the cryostat and to reduce the helium needed to cool the leads.

\section{ACKNOWLEDGMENTS}

This work was performed at the Brookhaven National Laboratory with the support of the Director of the Office of Energy Research, Office of High Energy and Nuclear Physics, High Energy Physics Division. United States Department of Energy under Contract number DE-AC02-76CH00016. The authors wish to acknowledge W. B. Sampson and A. K. Ghoh, BNL, for their measurement of lead tube resistivity.

\section{REFERENCES}

1 "Muon g-2 Design Report, BNL AGS E821, A New Precision Measurement of the Muon (g-2) Value at the Level of 0.35 ppm," Third Edition, Brookhaven National Laboratory Report, April 1994 Draft

2 Smits, R. G. et al. "Gas Cooled Electrical Leads for Use on Forced Cooled Superconducting Magnets", Advances in Cryogenic Engineering Vol 27, (1981), p 169, Plenum Press, New York

3 Wilson, M. N. Superconducting Magnets, (1983), Clarendon Press, Oxford

4 Sekulic, D. P., Uzeluc, Z. and Edeskuty, F. J. "Entropy Generation in a High Temperature Superconducting Current Lead", Cryogenics Vol 32, (1992), No. 12

5 "Copper and Brass Sales Inc. Stock Catalogue and Metals Hand Book", 1986 Edition 

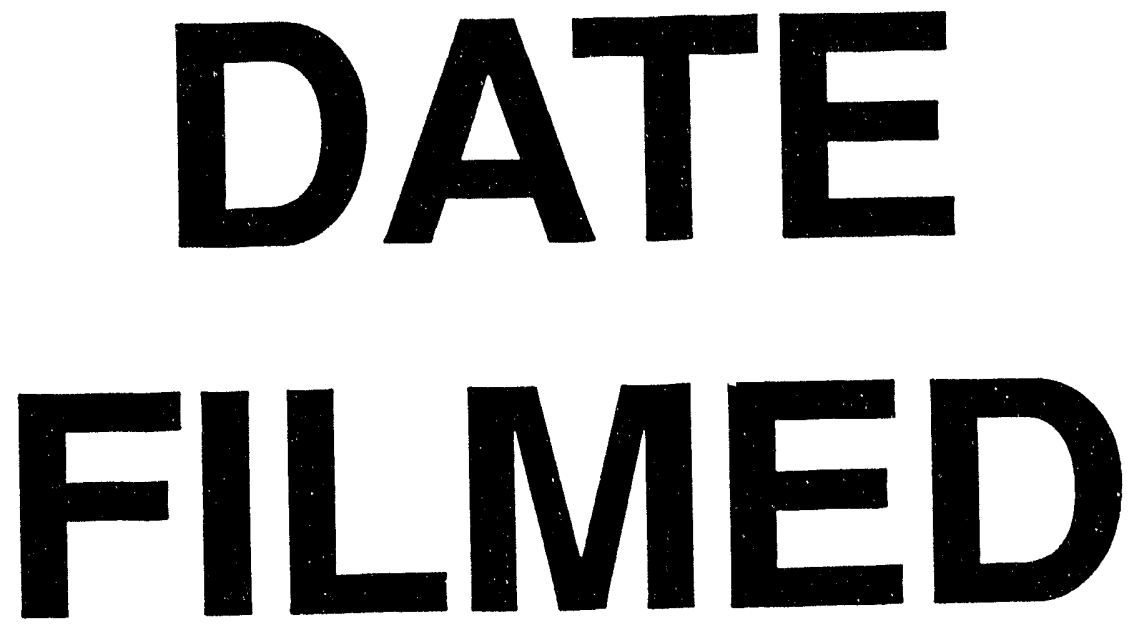

$8 / 22 / 94$

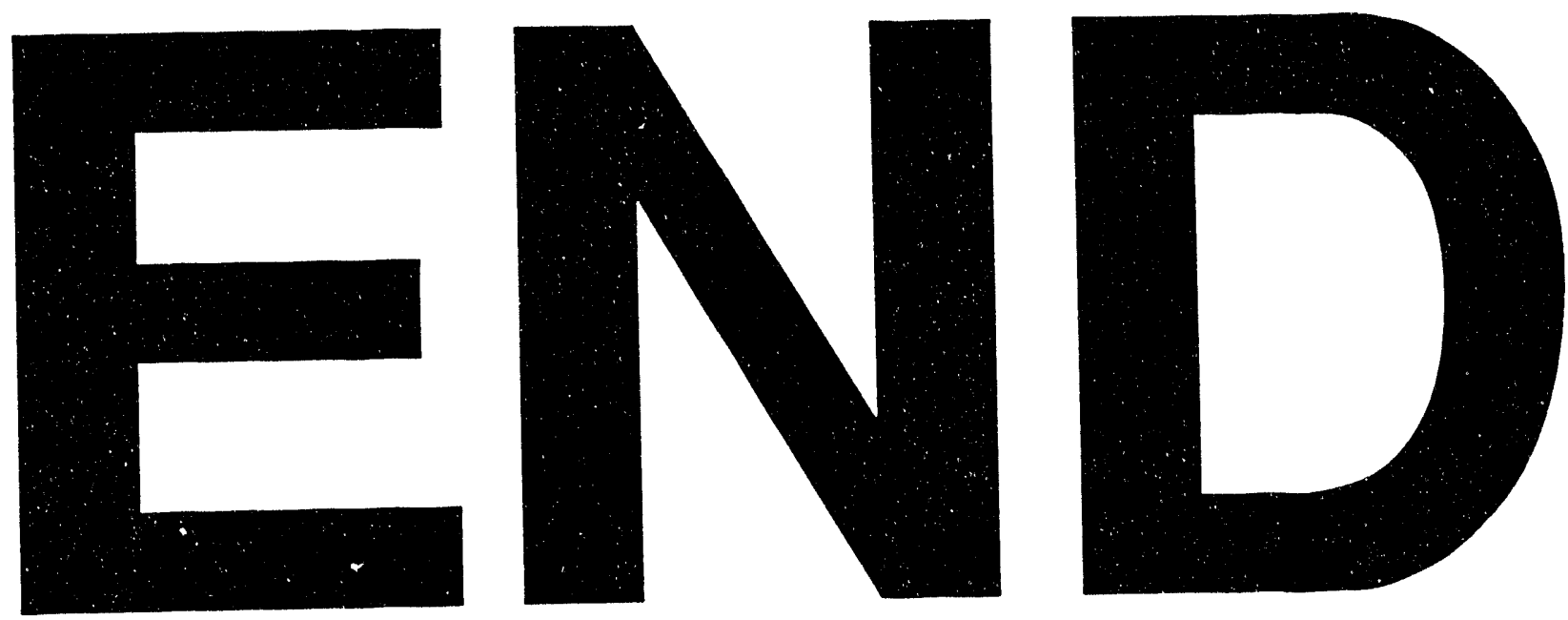


